\title{
Can Red Cell Distribution Width and Neutrophil/ Lymphocyte Ratio Be Used as Adjuvant Parameters to Support Computed Tomography in Prediction of Diagnosis and Severity of Acute Appendicitis in the Elderly Patients?
}

\author{
Mustafa Atabey*1 and Muhammed Aykota ${ }^{2}$ \\ ${ }^{1}$ Biruni University, Department of General Surgery, Turkey \\ ${ }^{2}$ Pamukkale University, Department of General Surgery, Turkey \\ *Corresponding author: Mustafa Atabey, Biruni University, Department of General Surgery, Turkey. \\ To Cite This Article: Mustafa Atabey, Muhammed Aykota, Can Red Cell Distribution Width and Neutrophil/Lymphocyte Ratio Be Used as Adju- \\ vant Parameters to Support Computed Tomography in Prediction of Diagnosis and Severity of Acute Appendicitis in the Elderly Patients?. Am J \\ Biomed Sci \& Res. 2021 - 11(6). AJBSR.MS.ID.001695. DOI: 10.34297/AJBSR.2021.11.001695.
}

Received: 泚 February 03, 2021; Published: 笽 February 11, 2021

\begin{abstract}
Aims: Acute appendicitis is the most common emergency surgical pathology in the general population. Even though numerous studies have been carried out to predict the clinical courses and treatment methods of the disease in patients with AA in recent years, clinical courses and findings of the disease may vary in the elderly patients. In the present study, we analyzed the correlation of RDW, WBC, CRP and NLR when used as inflammatory parameters with appendix diameter in elderly patients and assessed the predictive reliability in the preoperative diagnosis of elderly patients.
\end{abstract}

Methods and Material: This study included 120 patients aged over 65 years that were operated for AA between 2012-2020. The correlation of length of hospital stay, appendix diameter, computed tomography findings, pathology reports with CRP, WBC, NLR and RDW values were analyzed.

Results: CRP values were found to be $2.71 \pm 1.82$ and $3.38 \pm 3.92$ in the patients with negative pathology and acute appendicitis, respectively. A statistically significant difference was found between two groups. Mean WBC values were detected to be $13.52 \pm 5.94$ and $15.38 \pm 4.81$ in the patients with negative pathology and complicated appendicitis, respectively. In addition, mean RDW values were detected to be $12.88 \pm 2.96$ and $15.68 \pm 2.37$ in the patients with negative pathology and complicated appendicitis, respectively. A statistically significant difference was found also between these two groups.

Conclusion: Our results suggested that NLR values can be used not only as an adjuvant parameter in diagnosis to support the diagnosis in the patients that cannot undergo CT or those with suspected CT findings, but also they may provide contribution in predicting diagnosis and severity of AA in the elderly patient group. We conclude that RDW values can be also used as adjuvant parameters supporting other findings in diagnosis of AA unless an additional disease that elevates RDW values is present.

Keywords: Acute appendicitis, Elderly, RDW, NLR

\section{Introduction}

Elderly population is progressively increasing in parallel with aging world and it is predicted that elderly population over 65 years will reach $25 \%$ of total population (???) by 2050 [1]. The

increase in the elderly patient population will result in increased number of applications to emergency units by elderly population [2]. Acute appendicitis is the most common emergency surgical 
pathology in the general population while it is one of the most frequent emergency surgical pathologies in the elderly population [3]. The low diagnostic accuracy rates and higher mortality rates in elder population (???) than normal population in cases of delayed diagnosis make this emergency condition more critical and necessitate development of novel adjuvant diagnostic methods $[4,5]$. Even though, numerous studies have been carried out to predict clinical course and treatment method (medical/surgical) of the disease in the patients with AA in the recent years, clinical course and findings of the disease may vary in the elderly patient group and pose a necessity for further studies in this patient group $[5,6]$. Although, diagnostic laboratory and imaging methods reduced negative appendectomy rates, several complete blood count (CBC) parameters such as red blood cell width (RDW), Neutrophil/Lymphocyte ratio (NLR), Lymphocyte ratio and Platelet- Lymphocyte ratio are used in diagnosis of AA as supportive diagnostic tools [7-9].

Red blood cell width is a helpful, easily measurable, and lowcost method that is traditionally used in the differential diagnosis of anemia as well as being a component of complete blood count, and it has been accepted as the indicator of both inflammation and oxidative stress in many acute and chronic cases [10-12]. NLR has been defined as a diagnostic indicator in estimating prognosis of many acute and chronic pathologies such as mesenteric ischemia, cardiovascular disease, and cancer $[13,14]$. Although, the use of Computed Tomography (CT) is strongly recommended to reduce negative appendectomy rates in the elderly patients, diagnostic accuracy rates of CT are, nevertheless, lower than normal population and radiation exposure should be taken into consideration in some patient groups [5,15 \&16]. In the present study, we have analyzed the correlation of RDW and NLR used as inflammatory parameters with appendix diameter in the elderly patients and assessed its predictive reliability in preoperative diagnosis of the elderly patients.

\section{Materials and Methods}

The present study included 120 patients aged over 65 years that were operated for acute appendicitis between 2012-2020 in Denizli Pamukkale University and the Department of General Surgery of Medicana Hospital Sivas. The patients with a medical history including systemic disease and malignancy, chronic liver, and renal failure, and those that received blood transfusion therapy and anticoagulant medication were excluded from the study. Age, gender, surgical technique, CT findings and pathology reports of the patients were evaluated. The relationship of time duration to surgery, appendix diameter, computed tomography findings and pathology reports with CRP, CBC, NLR and RDW values were analyzed. The preoperatively performed computed tomography reports of the patients were as grouped as compatible with acute appendicitis, suspected findings of acute appendicitis, compatible with perforated appendicitis and the patients with appendiceal fecalith in the lumen. The pathology reports were distributed into three groups as normal (negative) appendix, acute appendicitis, and complicated appendicitis. Perforated appendicitis, gangrenous appendicitis and suppurative appendicitis were grouped as complicated appendicitis. The cutoff value for RDW was determined as 14.65 and the patients were distributed into two groups based on the cutoff value. The cutoff value of NLR was determined as 8.17 and the patients were evaluated in two groups based on the cutoff value.

\section{Statistical Analysis}

All statistical analyses were performed using the Statistical Software Package for the Social Sciences, Version 25.0 (SPSS, Chicago, IL, USA). The $\mathrm{p}<0.05$ value was accepted as statistically significant. Data normality was tested using Kolmogorov-Smirnov test and Kruskal Wallis- $\mathrm{H}$ test was applied to compare mean CRP, CBC, RDW and NLR values in terms of different appendiceal pathology and CT groups. Games Howell post hoc test was carried out for the comparisons between pathology and CT subgroups. Spearman's correlation analysis was performed in evaluation of the correlation relationship of appendix diameter and time duration to surgery with CRP, CBC, RDW and NLR. The categorical variables were compared by Fisher's Exact Test. As the final assessment, cutoff values and accuracy indices (sensitivity, specificity, and predictive values) for NLR and RDW were calculated by ROC analysis.

\section{Results}

Table 1 shows gender data, computed tomography, and pathology results of the 120 patients included in the study. Of the 120 patients; 56 (46.7\%) were female and 64 (53.3\%) were male. Mean age of the patients was 74.60 \pm 6.70 (min:67, max:90) years. Laparoscopic appendectomy was performed in 31 (25.8\%) patients. The pathology tests result of $22(18.3 \%)$ patients were reported as normal (negative). The pathology results of 45 (37.5\%) patients were compatible with acute appendicitis while the pathology tests result of $53(44.2 \%)$ patients were reported as complicated appendicitis.

As shown in Table 2, mean CRP values were found to be $2.71 \pm 1.82$ and $3.38 \pm 3.92$ in the patients with negative pathology and acute appendicitis, respectively. A statistically significant difference was found between two groups regarding mean CRP values ( $\mathrm{p}=0.002)$. Mean $\mathrm{CBC}$ values were detected to be $13.52 \pm 5.94$ and $15.38 \pm 4.81$ in the patients with negative pathology and complicated appendicitis, respectively. A statistically significant difference was found between two groups regarding mean $\mathrm{CBC}$ values ( $\mathrm{p}=0.033)$. Additionally, mean RDW values were detected to be $12.88 \pm 2.96$ and $15.68 \pm 2.37$ in the patients with negative pathology and complicated appendicitis, respectively. A statistically significant difference was found also between these two groups 
regarding mean $\mathrm{RDW}$ values $(\mathrm{p}=0.001)$. In the same manner, mean NLR values were encountered to be $7.23 \pm 5.81$ and10.55 \pm 5.55 in the patients with negative pathology and complicated appendicitis, respectively. A statistically significant difference was found between

NLR values of these groups $(\mathrm{p}=0.001)$.

Table 1: Demographic data.

\begin{tabular}{|c|c|c|}
\hline Variable (Categorical) & $\mathbf{N}$ & $\%$ \\
\hline \multicolumn{3}{|l|}{ Gender } \\
\hline Female & 56 & 46.7 \\
\hline Male & 64 & 53.3 \\
\hline Total & 120 & 100 \\
\hline \multicolumn{3}{|l|}{ Surgical Technique } \\
\hline Laparoscopic & 31 & 25.8 \\
\hline Open & 89 & 74.2 \\
\hline Total & 120 & 100 \\
\hline \multicolumn{3}{|l|}{$\mathrm{CT}$} \\
\hline Normal & 0 & 0 \\
\hline Acute appendicitis & 46 & 38.3 \\
\hline Suspected & 34 & 28.3 \\
\hline Perforation & 36 & 30 \\
\hline Fecalith & 4 & 3.4 \\
\hline Total & 120 & 100 \\
\hline \multicolumn{3}{|l|}{ Pathology } \\
\hline Negative & 22 & 18.3 \\
\hline Acute appendicitis & 45 & 37.5 \\
\hline Complicated & 53 & 44.2 \\
\hline Total & 120 & 100 \\
\hline
\end{tabular}

Table 2: The correlative evaluation of CRP, CBC, RDW and NLR values with pathology subgroups.

\begin{tabular}{|c|c|c|c|c|c|c|}
\hline & & \multirow{2}{*}{ Number (\%) } & \multirow{2}{*}{$\begin{array}{c}\text { Mean } \pm \text { SD } \\
\text { Lower limit }\end{array}$} & \multicolumn{2}{|c|}{ 95\% Confidence Interval } & \multirow{2}{*}{$\mathbf{p}$} \\
\hline & & & & Upper limit & & \\
\hline \multicolumn{7}{|l|}{ CRP } \\
\hline & Negative & $22(18.3)$ & $2.71 \pm 1.82$ & 1.91 & 3.52 & 0.002 \\
\hline & Acute appendicitis & $45(37.5)$ & $3.38 \pm 3.92$ & 2.2 & 4.56 & \\
\hline & Complicated & $53(44.2)$ & $6.03 \pm 6.12$ & 4.34 & 7.72 & \\
\hline & Total & $120(100.0)$ & $4.43 \pm 4.97$ & 3.53 & 5.33 & \\
\hline \multicolumn{7}{|l|}{$\mathrm{CBC}$} \\
\hline & Negative & $22(18.3)$ & $13.52 \pm 5.94$ & 10.93 & 16.11 & 0.033 \\
\hline & Acute appendicitis & $45(37.5)$ & $12.99 \pm 4.27$ & 11.7 & 14.27 & \\
\hline & Complicated & $53(44.2)$ & $15.38 \pm 4.81$ & 14.05 & 16.71 & \\
\hline & Total & $120(100.0)$ & $14.14 \pm 4.91$ & 13.25 & 15.03 & \\
\hline \multicolumn{7}{|l|}{ RDW } \\
\hline & Negative & $22(18.3)$ & $12.88 \pm 2.96$ & 11.57 & 14.2 & 0.001 \\
\hline & Acute appendicitis & $45(37.5)$ & $14.65 \pm 1.67$ & 14.15 & 15.15 & \\
\hline & Complicated & $53(44.2)$ & $15.68 \pm 2.37$ & 15.02 & 16.33 & \\
\hline & Total & $120(100.0)$ & $14.78 \pm 2.46$ & 14.33 & 15.22 & \\
\hline
\end{tabular}

As presented in Table 3, no statistically significant correlation was found between appendix diameter and the levels of CRP, CBC, RDW and NLR (respectively; $r=0.128, p=0.165 ; r=0.029, p=0.753$; $\mathrm{r}=0.104, \mathrm{p}=0.257 ; \mathrm{r}=0.100, \mathrm{p}=0.276$ ). 


\begin{tabular}{|c|c|c|c|c|c|c|}
\hline \multirow{2}{*}{ NLR } & & & & & & \\
\hline \multirow{7}{*}{} & Negative & $22(18.3)$ & $7.23 \pm 5.81$ & 4.65 & 9.81 & 0.001 \\
\cline { 2 - 7 } & Acute appendicitis & $45(37.5)$ & $8.11 \pm 6.64$ & 6.11 & 10.1 & 12.09 \\
\cline { 2 - 7 } & Complicated & $53(44.2)$ & $10.55 \pm 5.55$ & 9.02 & 10.14 & \\
\cline { 2 - 7 } & Total & $120(100.0)$ & $9.03 \pm 6.14$ & 7.92 & \\
\hline
\end{tabular}

Note*: Kruskal Wallis-H test

Table 3: The correlative evaluation between appendix diameter and laboratory values of the patients.

\begin{tabular}{|c|c|c|c|c|c|}
\hline \multicolumn{2}{|c|}{} & CRP & CBC & RDW & NLR \\
\hline \multirow{3}{*}{ Diameter } & $\mathrm{r}$ & 0.128 & 0.029 & 0.104 & 0.1 \\
\cline { 2 - 7 } & $\mathrm{p}$ & 0.165 & 0.753 & 0.257 & 0.276 \\
\cline { 2 - 7 } & $\mathrm{N}$ & 120 & 120 & 120 & 120 \\
\hline
\end{tabular}

Note*: Spearman's correlation analysis

The relationship between CT findings and laboratory values were analyzed in Table 4. No statistically significant correlation was determined between CRP, CBC, RDW and NLR values and CT subgroups (respectively; $\mathrm{p}=0.183 ; \mathrm{p}=0.407 ; \mathrm{p}=0.172 ; \mathrm{p}=0.467$ ).

As manifested in Table 5, a statistically significantly weak negative correlation was detected between time duration to surgery and NLR levels ( $\mathrm{r}=-0.253, \mathrm{p}=0.005)$. No statistically significant correlation was detected between time duration to surgery and CRP, CBC and RDW levels (respectively; $r=0.045, p=0.627 ; r=-0.110$, $\mathrm{p}=0.231 \mathrm{r}=0.107, \mathrm{p}=0.243$ ).

The sensitivity, specificity, PPV and NPV of RDW were assessed to be $51.00 \%, 75.00 \%, 51.00 \%$ and $75.00 \%$ in detection of acute appendicitis, respectively. AUC and standard error were determined to be 0.63 (95\% confidence interval (CI), 0.48; 0.78) and 0.07 $(p=0.045)$ in the ROC analysis designed to identify the sensitivity and specificity of RDW, respectively (Figure 1, Table 6).

The sensitivity, specificity, PPV and NPV of NLR in detection of acute appendicitis were assessed to be $72.70 \%, 73.50 \%, 27.30 \%$ and $26.53 \%$, respectively. AUC and standard error were determined to be 0.86 (95\% confidence interval (CI), 0.79; 0.93) and 0.035 $(p<0.001)$ in the ROC analysis designed to identify the sensitivity and specificity of NLR, respectively (Figure 2, Table 7).

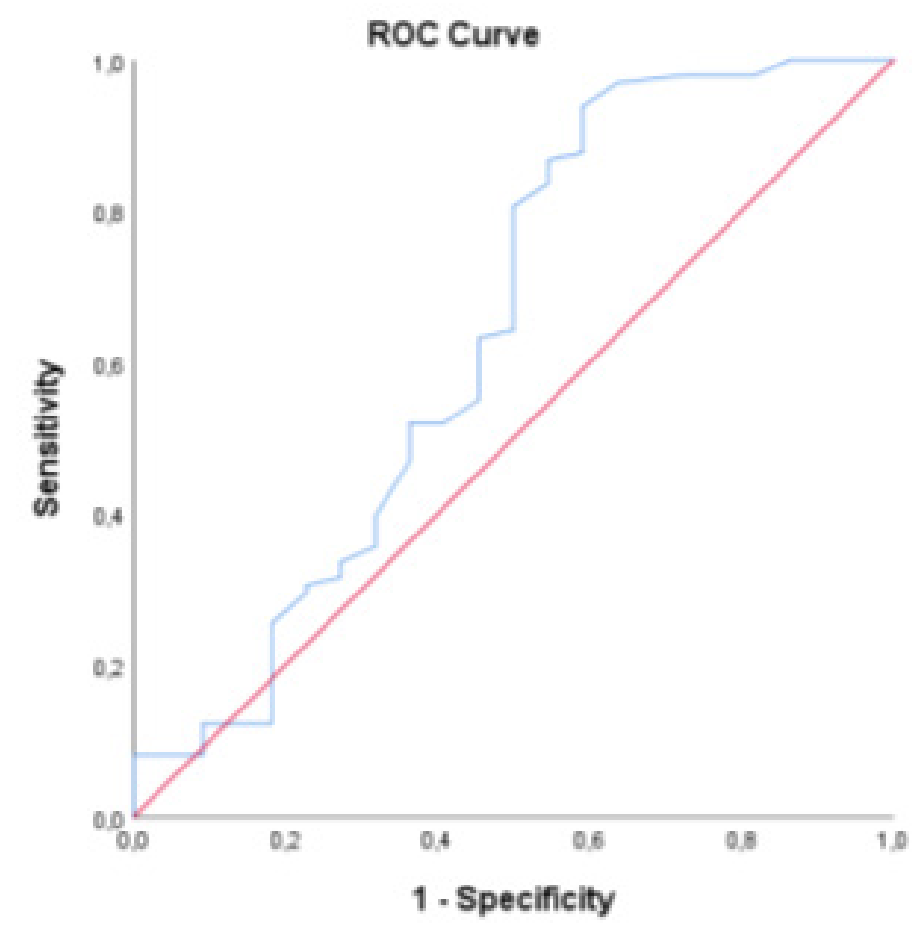

Figure 1: ROC curve of RDW in detection of appendicitis. 


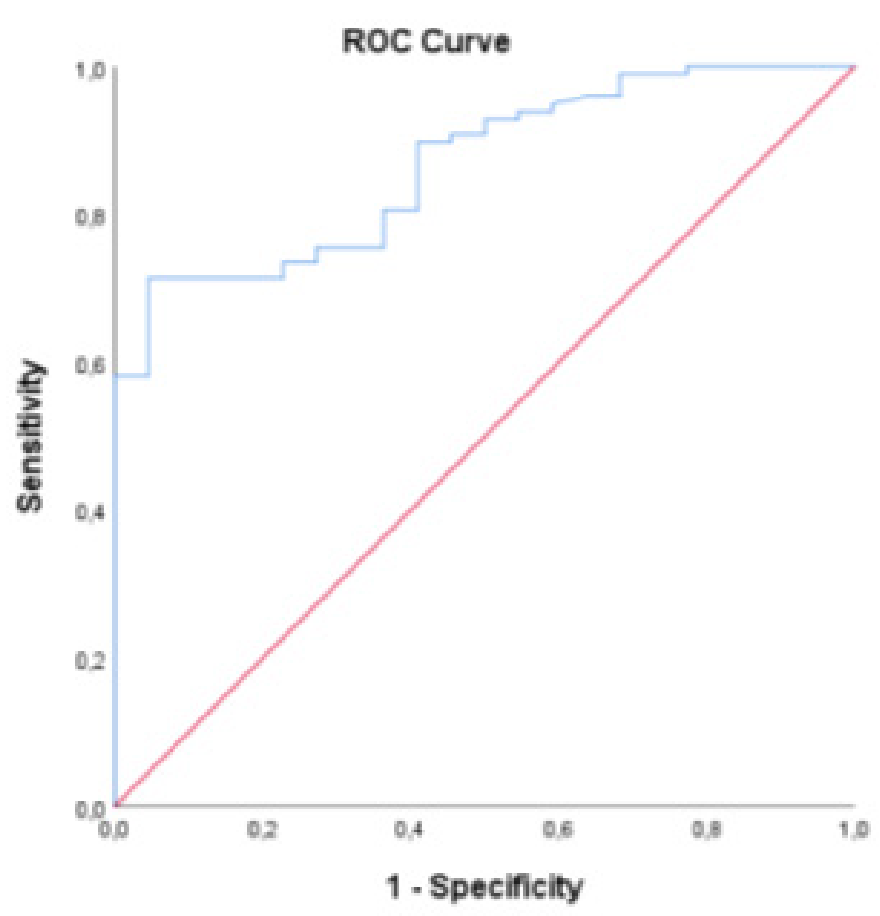

Figure 2: ROC curve of NLR in detection of appendicitis.

Table 4: The correlative evaluation between CT groups and laboratory values of the patients.

\begin{tabular}{|c|c|c|c|c|c|c|}
\hline & & \multirow[b]{2}{*}{ Number (\%) } & \multirow[b]{2}{*}{ Mean \pm SD } & \multicolumn{2}{|c|}{ 95\% Confidence Interval } & \multirow{2}{*}{$\mathbf{p}$} \\
\hline & & & & Lower limit & Upper limit & \\
\hline \multicolumn{7}{|l|}{ CRP } \\
\hline & $\begin{array}{l}\text { Acute appen- } \\
\text { dicitis }\end{array}$ & $46(14.2)$ & $3.97 \pm 4.56$ & 2.62 & 5.33 & 0.183 \\
\hline & Suspected & $34(10.5)$ & $3.36 \pm 3.00$ & 2.32 & 4.41 & \\
\hline & Perforation & $36(11.1)$ & $6.09 \pm 6.64$ & 3.84 & 8.33 & \\
\hline & Fecalith & $4(1.2)$ & $3.76 \pm 2.62$ & 0.41 & 7.49 & \\
\hline & Total & $120(100.0)$ & $4.43 \pm 4.97$ & 3.53 & 5.33 & \\
\hline \multicolumn{7}{|l|}{ СBC } \\
\hline & $\begin{array}{l}\text { Acute appen- } \\
\text { dicitis }\end{array}$ & $46(14.2)$ & $13.41 \pm 4.22$ & 12.15 & 14.66 & 0.407 \\
\hline & Suspected & $34(10.5)$ & $14.23 \pm 5.31$ & 12.37 & 16.08 & \\
\hline & Perforation & $36(11.1)$ & $15.25 \pm 5.15$ & 13.51 & 17 & \\
\hline & Fecalith & $4(1.2)$ & $11.89 \pm 6.49$ & 1.56 & 22.22 & \\
\hline & Total & $120(100.0)$ & $14.14 \pm 4.91$ & 13.25 & 15.03 & \\
\hline \multicolumn{7}{|l|}{ RDW } \\
\hline & $\begin{array}{l}\text { Acute appen- } \\
\text { dicitis }\end{array}$ & $46(14.2)$ & $14.50 \pm 1.44$ & 14.07 & 14.93 & 0.172 \\
\hline & Suspected & $34(10.5)$ & $14.44 \pm 1.84$ & 13.79 & 15.08 & \\
\hline & Perforation & $36(11.1)$ & $15.04 \pm 1.39$ & 14.56 & 15.51 & \\
\hline & Fecalith & $4(1.2)$ & $14.65 \pm 0.86$ & 13.27 & 16.02 & \\
\hline & Total & $120(100.0)$ & $14.65 \pm 1.54$ & 14.37 & 14.93 & \\
\hline
\end{tabular}




\begin{tabular}{|l|c|c|c|c|c|c|}
\hline NLR & & & & & \\
\hline & $\begin{array}{c}\text { Acute appen- } \\
\text { dicitis }\end{array}$ & $46(14.2)$ & $7.58 \pm 6.26$ & 5.72 & 9.44 \\
\hline & Suspected & $34(10.5)$ & $7.40 \pm 5.46$ & 5.5 & 9.31 \\
\hline & Perforation & $36(11.1)$ & $9.35 \pm 7.14$ & 6.93 & 11.76 & 10.21 \\
\hline & Fecalith & $4(1.2)$ & $5.11 \pm 3.20$ & 0 & 9.11 & \\
\hline
\end{tabular}

Table 5: The correlation of time duration to surgery with CRP, CBC, RDW and NLR values of the patients.

\begin{tabular}{|c|c|c|c|c|c|}
\hline & & CRP & CBC & RDW & NLR \\
\hline \multirow{3}{*}{ Time duration to surgery } & $\mathrm{r}$ & 0.045 & -0.11 & 0.107 & $-.253^{* *}$ \\
\hline & $\mathrm{p}$ & 0.627 & 0.231 & 0.243 & 0.005 \\
\hline & $\mathrm{N}$ & 120 & 120 & 120 & 120 \\
\hline
\end{tabular}

Table 6.

\begin{tabular}{|c|c|c|c|}
\hline \multirow{2}{*}{ Cutoff } & Appendicitis & Normal & \multirow{2}{*}{ Total } \\
\cline { 2 - 4 } & \multicolumn{2}{|c|}{ N } & 5 \\
\hline$<14.65$ & 51 & 15 & 56 \\
\hline$\geq 14.65$ & 49 & 20 & 64 \\
\hline Total & 100 & 120 \\
\hline
\end{tabular}

Table 7.

\begin{tabular}{|c|c|c|c|}
\hline \multirow{2}{*}{ Cutoff } & Appendicitis & Normal & \multirow{2}{*}{ Total } \\
\hline & \multicolumn{2}{|c|}{$\mathbf{N}$} & \\
\hline$<8,17$ & 16 & 26 & 42 \\
\hline$\geq 8.17$ & 6 & 72 & 78 \\
\hline Total & 22 & 98 & 120 \\
\hline
\end{tabular}

\section{Discussion}

Acute appendicitis is one of the major diseases that has been addressed by many studies to elevate diagnostic accuracy since it has a unsteady clinical course and progressive nature that may lead to high morbidity and mortality rates in the elderly population when remains untreated $[5,6,15]$. The low diagnostic accuracy based on clinical findings and longer time interval before hospital admission in elderly patient group than younger patient group increase probability of perforation and progression to complicated appendicitis and consequently increase the use of imaging techniques such as Computed Tomography [17-19]. Although, CT is a frequently used imaging technique with a high diagnostic accuracy in diagnosis of the adult patients with AA and reduces negative appendectomy rates, it is recommended to correlate imaging results with different clinical scoring systems and laboratory parameters to elevate the imaging accuracy rates in the elderly patients $[5,20]$. The extensive use of CT is accompanied with several problems such as increased exposure to ionizing radiation and high treatment costs [21].

Low diagnostic sensitivity of $\mathrm{CBC}$ and CRP values led to development of novel studies related with other $\mathrm{CBC}$ parameters for confirmation of the diagnosis and numerous studies have been carried out on that subject [22-24].

Red blood cell width is a measure of variability in red cell size. RDW, being essentially used in differential diagnosis of anemia, is an automatic measure of heterogeneity of red blood cell size. It is calculated by dividing the standard deviation of red blood cell volume to mean corpuscular volume and multiplying it by 100 to express the result as percentage. The changes in RDW value have been encountered in some inflammatory and infectious pathologies such as inflammatory bowel disease, celiac disease, acute pancreatitis, rheumatoid arthritis, bacteremia, sepsis and septic shock, and accepted as an indicator used in prediction of general mortality rate in the public [25-27]. In our study, a statistically significant increase was determined in the AA and complicated appendicitis (CA) groups than negative appendicitis (NA) when RDW values were compared with pathology subgroups. The sensitivity, specificity, and AUC values of RDW were found as 51.00\%, 75.00\%and AUC: 0.63 by the ROC analysis performed in the context of our study, respectively. We conclude that high RDW values were resulting from increased level of reticulocytes entering the circulation due to suppression of erythrocyte maturation by 
the inflammatory mediators entering the systemic circulation [27]. We detected no correlation of RDW with appendix diameter encountered by CT and time interval to surgery of the patients. Tanrikulu et al. [28] have also reported that high RDW values may be determined in AA. Similarly, Haghi et al. [29] have suggested that RDW values may be used as a parameter in diagnosis of AA in the adult patients and helpful in avoiding unnecessary surgeries. On the other hand, Narcl et al. [30] have found lower RDW values in the patients with AA in contrast with our study. We attribute high RDW values in the elderly population to the longer time interval before hospital admission and long-term exposure to inflammatory mediators in these patients $[19,27]$.

In our study, we determined statistically significant increases in CBC and CRP levels of the AA and CA groups compared with NA group as the most used laboratory tests in the emergency units. This result is consistent with the strong recommendations in the literature related with routine testing of these diagnostic parameters5. The evaluation of CRP and CBC comparatively with CT indicated that $\mathrm{CBC}$ and CRP values increased as disease severity increased, however, this increase was not found to be statistically significant. Additionally, these two values were found correlated with time duration to surgery.

NLR is an inflammatory parameter with an increased use in the routine clinical practice as a more specific diagnostic parameter than CBC since it increases in case of AA and many other inflammatory entities $[13,14,24]$. High CBC count is important in diagnosis of AA, however, it has no diagnostic value. The physiological response of circulatory leukocytes leads to elevated neutrophil and decreased lymphocyte counts. Therefore, the ratio between these 2 subgroups (NLR) is used as an inflammation parameter [31].

In our study, increased NLR values in the AA and CA groups was found statistically significant. The sensitivity, specificity, and AUC values of NLR were found as $72.70 \%, 75.00 \%$ and AUC: 0.86 by the ROC analysis, respectively. It was also detected that NLR values increased as disease severity increased. Jung et al. [24] have stated that NLR has a strong predictive value in perforated appendicitis in the elderly patients. In a similar way, Kelly et al. [32] have noted that NLR value has a predictive value associated with severity of appendicitis, length of hospital stays and postoperative complications. Some studies have suggested that medical treatment should be considered in the patients with low NLR values [33]. On the other hand, Cigsar et al. [34] have stated that testing NLR is not useful in diagnosis of AA in the elderly patient group whereas it may be useful in the non-geriatric patient group.

In the present study, we excluded the additional pathologies except demographic data that may affect neutrophil response. In the light of these data, we concluded that NLR values are useful in diagnosis and prediction of clinical course of the disease in the elderly patients. Additionally, we also consider that NLR should be evaluated as an inflammatory parameter to be taken into consideration primarily in the first emergency examination of the patients that cannot undergo CT scan [35]. The high probability of advanced stage of the disease at the time of hospital admission in the elderly patient group requires rapid surgery as well as rapid diagnosis $[5,36]$. We have detected in our study that time duration to surgery was shorter in the patients with increased levels of NLR. This finding suggests that clinical findings of these patients were more remarkable when analyzed retrospectively. It also supports our findings associated with disease severity.

Beside these findings, we have also determined that the parameters tested in our study were not correlated with appendix diameter. The correlative evaluation of CT findings with NLR values indicated a higher increase in CA group compared with the AA and the suspected AA groups, and that higher increase was interpreted to be remarkable, although insignificant. In the light of all these data, we conclude that NLR is a useful parameter that should be correlated with CT or should be used in diagnosis of the disease and prediction of the severity in the cases with suspected CT findings or those cannot undergo CT.

The high morbidity rates of negative appendectomy in the elderly patient group obligate the surgeons to be more careful in establishment of the diagnosis. Although, AA is an emergency pathology with remarkable signs and symptoms, there is no single parameter available to diagnose easily, therefore, it should be interpreted by correlation of clinical, laboratory and radiological imaging.

\section{Conclusions}

As a conclusion, our results suggested that NLR values can be used not only as an adjuvant parameter in diagnosis to support the diagnosis in the patients that cannot undergo CT or those with suspected CT findings, but also to contribute in predicting diagnosis and severity of AA in the elderly patient group. We conclude that RDW values can be also used as adjuvant parameters supporting other findings in diagnosis of AA unless an additional disease that elevates RDW values is present. The further prospective randomized studies with a larger sampling size are needed to clarify the diagnostic uncertainties in this patient group.

\section{References}

1. (2020) Healthy ageing. World Health Organization Europe.

2. de Dombal FT (1994) Acute abdominal pain in the elderly. J Clin Gastroenterol 1994;19(4):331-335.

3. Omari AH, Khammash MR, Qasaimeh GR, Shammari AK, Yaseen MKB, et al. (2014) Acute appendicitis in the elderly: risk factors for perforation. World J Emerg Surg WJES 9(1): 6.

4. Cigsar G, Yildirim AC, Anuk T, Hakan Guzel, Elnare Gunal, et al. (2017) Neutrophil to Lymphocyte Ratio on Appendectomy of Geriatric and Nongeriatric Patients. J Invest Surg 30(5): 285-290. 
5. Fugazzola P, Ceresoli M, Agnoletti V, Ferdinando Agresta, Bruno Amato, et al. (2020) The SIFIPAC/WSES/SICG/SIMEU guidelines for diagnosis and treatment of acute appendicitis in the elderly (2019 edition). World J Emerg Surg 15(1):19.

6. Dhillon NK, Barmparas G, Lin TL, Rodrigo F Alban, Nicolas Melo, et al. (2019) Unexpected complicated appendicitis in the elderly diagnosed with acute appendicitis. Am J Surg 218(6): 1219-1222.

7. Søndenaa K, Buan B, Søreide JA, A Nysted, E Andersen, et al. (1992) Rapid C-reactive protein (CRP) measurements in the diagnosis of acute appendicitis. Scand J Clin Lab Invest. 1992;52(7): 585-589.

8. Bayrak S, Tatar C, Cakar E, Sukru Colak, Mehmet Emin Gunes, et al. (2019) Evaluation of the predictive power of laboratory markers in the diagnosis of acute appendicitis in the elderly. North Clin Istanb 6(3): 293-301.

9. Ozan E, Ataç GK, Alişar K, Alhan A (2017) Role of inflammatory markers in decreasing negative appendectomy rate: A study based on computed tomography findings. Ulus Travma Ve Acil Cerrahi Derg Turk J Trauma Emerg Surg TJTES 23(6): 477-482.

10. Pan J, Borné Y, Engström G (2019) The relationship between red cell distribution width and all-cause and cause-specific mortality in a general population. Sci Rep 9(1): 16208.

11. Dong X, Liao Y, Chen K, Yong Fang, Weiguo Li, et al. (2015) Elevated red blood cell distribution width in benign prostatic hyperplasia patients with metabolic syndrome. Int J Clin Exp Med 8(1): 1213-1219.

12. Salvagno GL, Sanchis Gomar F, Picanza A, Lippi G (2015) Red blood cell distribution width: A simple parameter with multiple clinical applications. Crit Rev Clin Lab Sci 52(2): 86-105.

13. Shimada H, Takiguchi N, Kainuma O, Hiroaki Soda, Atsushi Ikeda, et al. (2010) High preoperative neutrophil-lymphocyte ratio predicts poor survival in patients with gastric cancer. Gastric Cancer 13(3): 170-176.

14. Aktimur R, Cetinkunar S, Yildirim K, Aktimur SH, Ugurlucan M, et al. (2016) Neutrophil-to-lymphocyte ratio as a diagnostic biomarker for the diagnosis of acute mesenteric ischemia. Eur J Trauma Emerg Surg 42(3): 363-368.

15. Pooler BD, Lawrence EM, Pickhardt PJ (2012) MDCT for suspected appendicitis in the elderly: diagnostic performance and patient outcome. Emerg Radiol 19(1): 27-33.

16. Monajemzadeh M, Hagghi Ashtiani MT, Montaser Kouhsari L, Ahmadi H, Zargoosh H, et al. (2011) Pathologic Evaluation of Appendectomy Specimens in Children: Is Routine Histopatholgic Examination Indicated? Iran J Pediatr 21(4): 485-490.

17. Körner H, Söndenaa K, Söreide JA, E Andersen, A Nysted, et al. (1997) Incidence of acute nonperforated and perforated appendicitis: agespecific and sex-specific analysis. World J Surg 21(3): 313-317.

18. Hui TT, Major KM, Avital I, Hiatt JR, Margulies DR (2002) Outcome of elderly patients with appendicitis: effect of computed tomography and laparoscopy. Arch Surg 137(9): 995-998.

19. Kraemer M, Franke C, Ohmann C, Yang Q Acute Abdominal Pain Study Group. (2000) Acute appendicitis in late adulthood: incidence, presentation, and outcome. Results of a prospective multicenter acute abdominal pain study and a review of the literature. Langenbecks Arch Surg 385(7): 470-481.

20. van Randen A, Bipat S, Zwinderman AH, Ubbink DT, Stoker J, et al. (2008) Acute appendicitis: meta-analysis of diagnostic performance of CT and graded compression US related to prevalence of disease. Radiology 249(1): 97-106.
21. Verma R, Grechushkin V, Carter D, Barish M, Pryor A, et al. (2015) Use and accuracy of computed tomography scan in diagnosing perforated appendicitis. Am Surg 81(4): 404-407.

22. Mostbeck G, Adam EJ, Nielsen MB, Michel Claudon, Dirk Clevert, et al. (2016) How to diagnose acute appendicitis: ultrasound first. Insights Imaging 7(2): 255-263.

23. Yu CW, Juan LI, Wu MH, Shen CJ, Wu JY, et al. (2013) Systematic review and meta-analysis of the diagnostic accuracy of procalcitonin, C-reactive protein and white blood cell count for suspected acute appendicitis. Br J Surg 100(3):322-329.

24. Jung SK, Rhee DY, Lee WJ, Seon Hee Woo, Seung Hwan Seol, et al. (2017) Neutrophil-to-lymphocyte count ratio is associated with perforated appendicitis in elderly patients of emergency department. Aging Clin Exp Res 29(3): 529-536.

25. Lippi G, Salvagno GL, Guidi GC (2014) Red blood cell distribution width is significantly associated with aging and gender. Clin Chem Lab Med 52(9): e197-199.

26. Salvagno GL, Sanchis Gomar F, Picanza A, Lippi G (2015) Red blood cell distribution width: A simple parameter with multiple clinical applications. Crit Rev Clin Lab Sci 52(2): 86-105.

27. Sadaka F, O'Brien J, Prakash S (2013) Red cell distribution width and outcome in patients with septic shock. J Intensive Care Med 28(5): 307313.

28. Tanrikulu CS, Tanrikulu Y, Sabuncuoglu MZ, Karamercan MA, Akkapulu $\mathrm{N}$, et al. (2014) Mean platelet volume and red cell distribution width as a diagnostic marker in acute appendicitis. Iran Red Crescent Med J 16(5): e10211.

29. Haghi AR, Pourmohammad P, Rabiee MAS (2019) Accuracy of Mean Platelet Volume (MPV) and Red Cell Distribution Width (RDW) for the Diagnosis of Acute Appendicitis: Evaluation of Possible New Biomarkers. Adv J Emerg Med 4(2): e20.

30. Narci H, Turk E, Karagulle E, Togan T, Karabulut K (2013) The role of red cell distribution width in the diagnosis of acute appendicitis: a retrospective case-controlled study. World J Emerg Surg 8(1): 46.

31. Panagiotopoulou IG, Parashar D, Lin R, S Antonowicz, A D Wells, et al. (2013) The diagnostic value of white cell count, C-reactive protein and bilirubin in acute appendicitis and its complications. Ann R Coll Surg Engl 95(3): 215-221.

32. Kelly ME, Khan A, Riaz M, Jarlath C Bolger, Fidal Bennani, et al. (2015) The Utility of Neutrophil-to-Lymphocyte Ratio as a Severity Predictor of Acute Appendicitis, Length of Hospital Stay and Postoperative Complication Rates. Dig Surg 32(6):459-463.

33. Shimizu T, Ishizuka M, Kubota K (2016) A lower neutrophil to lymphocyte ratio is closely associated with catarrhal appendicitis versus severe appendicitis. Surg Today 46(1): 84-89.

34. Cigsar G, Yildirim AC, Anuk T, Hakan Guzel, Elnare Gunal, et al. (2017) Neutrophil to Lymphocyte Ratio on Appendectomy of Geriatric and Nongeriatric Patients. J Invest Surg 30(5): 285-290.

35. Hajibandeh S, Hajibandeh S, Hobbs N, Mansour M (2020) Neutrophil-tolymphocyte ratio predicts acute appendicitis and distinguishes between complicated and uncomplicated appendicitis: A systematic review and meta-analysis. Am J Surg 219(1): 154-163.

36. Tantarattanapong S, Arwae N (2018) Risk factors associated with perforated acute appendicitis in geriatric emergency patients. Open Access Emerg Med OAEM 10: 129-134. 